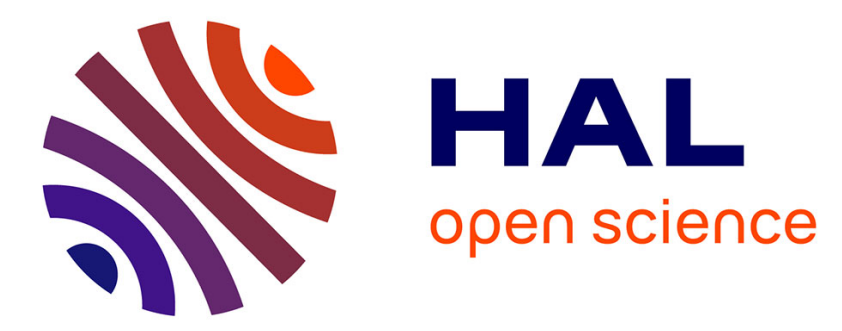

\title{
Optimal duration of dual antiplatelet therapy post percutaneous coronary intervention in acute coronary syndrome
}

\author{
Pierre Deharo, Thomas Cuisset
}

\section{To cite this version:}

Pierre Deharo, Thomas Cuisset. Optimal duration of dual antiplatelet therapy post percutaneous coronary intervention in acute coronary syndrome. Trends in Cardiovascular Medicine, 2020, 30 (4), pp.198-202. 10.1016/j.tcm.2019.05.008 . hal-03149583

\section{HAL Id: hal-03149583 \\ https://hal-amu.archives-ouvertes.fr/hal-03149583}

Submitted on 23 Feb 2021

HAL is a multi-disciplinary open access archive for the deposit and dissemination of scientific research documents, whether they are published or not. The documents may come from teaching and research institutions in France or abroad, or from public or private research centers.
L'archive ouverte pluridisciplinaire HAL, est destinée au dépôt et à la diffusion de documents scientifiques de niveau recherche, publiés ou non, émanant des établissements d'enseignement et de recherche français ou étrangers, des laboratoires publics ou privés.

\section{(ㅇ)(1) $\$$}

Distributed under a Creative Commons Attribution - NonCommercial - NoDerivatives| 4.0 


\title{
Optimal duration of dual antiplatelet therapy post percutaneous coronary intervention in acute coronary syndrome
}

\author{
Pierre Deharo $^{\mathrm{a}, \mathrm{b}, \mathrm{c}, *}$, Thomas Cuisset $^{\mathrm{a}, \mathrm{c}, \mathrm{d}}$ \\ a Département de Cardiologie, CHU Timone, Marseille, F-13385 France \\ ${ }^{\mathrm{b}} \mathrm{C} 2 \mathrm{VN}$, INSERM, INRA, AMU, France \\ 'Aix-Marseille Université, Faculté de Médecine, F-13385, Marseille, France \\ ${ }^{\mathrm{d}}$ Aix Marseille Univ, Inserm, Inra, C2VN, Marseille, France
}

\section{A R T I C L E I N F O}

\section{Keywords:}

Dual antiplatelet therapy

Acute coronary syndrome

Percutaneous coronary intervention

\begin{abstract}
A B S T R A C T
Dual antiplatelet therapy (DAPT), with aspirin plus a P2Y12 inhibitor agent, is the cornerstone treatment after percutaneous coronary intervention for acute coronary syndrome. Based on randomized clinical trial using aspirin and clopidogrel, a DAPT duration of 12 months has been recommended after an acute coronary syndrome. Despite the development of more potent antiplatelet agents (i.e. prasugrel and ticagrelor) and the reduction in ischemic recurrences after acute coronary syndrome, 12 months DAPT currently remains the gold standard. However, a significant proportion of patients experience recurrent ischemic events beyond the first 12 months after an acute coronary syndrome. Meanwhile, with more effective antiplatelet agent, bleeding has become a major safety concern on DAPT. Therefore, the ischemic and bleeding risk balance is central considering the duration of DAPT after an acute coronary syndrome. This review aims to report the evidence for an optimization and individualization of DAPT duration after an acute coronary syndrome.
\end{abstract}

(c) 2019 The Author(s). Published by Elsevier Inc. This is an open access article under the CC BY-NC-ND license. (http://creativecommons.org/licenses/by-nc-nd/4.0/)

\section{Dual antiplatelet therapy (DAPT) duration: introduction}

Oral DAPT including aspirin and P2Y12 inhibitors is widely used with proven benefit for the prevention of recurrent ischemic events after acute coronary syndrome (ACS) $[1,2]$. Platelets play a central role in atherothrombosis during acute coronary syndrome (ACS) and adequate platelet inhibition is crucial to minimize the risk of recurrent ischemic events. An association of aspirin and a second antiplatelet agent (clopidogrel, prasugrel or ticagrelor) is the current standard antiplatelet therapy following ACS for one year and is associated with improved ischemic outcomes, mainly driven by lower recurrence of stent thrombosis [1,2].

\section{Dual antiplatelet therapy (DAPT) duration: initial guidelines}

Current guidelines recommend the use of DAPT for 12 months since Clopidogrel in Unstable Angina to Prevent Recurrent Events

\footnotetext{
th Financial disclosure: Pierre Deharo: lectures fees from SANOFI. Thomas CUISSET: Consulting and Lecture Fees from ASTRA ZENECA, SANOFI.

Acknowledgments: None.

* Corresponding author at: Department of Cardiology, University Hospital la Timone, 13005 Marseille, France.

E-mail address: deharopierre@gmail.com (P. Deharo).
}

(CURE) results in 2001 [1-4]. CURE trial showed the superiority of DAPT with aspirin plus clopidogrel versus aspirin alone $(20 \%$ of ischemic risk reduction) [1,2]. The mean duration of DAPT in this study was 9 months (from 3 to 12). Following this trial, clopidogrel has been considered the gold standard therapy after an ACS with a 1 year duration $[1,2]$. Since then, the European and American guidelines recommend the use of DAPT for 12 months after an acute coronary syndrome with the highest level of evidence (I A) [3,4]. However, despite those 12 months of DAPT, a significant proportion of patients did experience recurrent ischemic events within this period, and newer P12Y12 blockers have been developed [5,6]. TRITON TIMI 38 (Prasugrel versus Clopidogrel in Patients with Acute Coronary Syndromes) trial proved the superiority of a DAPT with aspirin prasugrel versus aspirin clopidogrel for a mean duration of 14.5 months (from 6 to 15 months) [5]. Later, the PLATO (Ticagrelor versus Clopidogrel in Patients with Acute Coronary Syndromes) study showed the superiority of ticagrelor plus aspirin versus clopidogrel plus aspirin for a mean duration of 9.3 months (from 6 to 12 months) [6]. Those 2 studies consolidated the 12 months DAPT duration recommendation with newer P2Y12 blockers used in first intention. In both studies, newer P2Y12 blockers reduced the risk for ischemic recurrence but were associated with increased bleeding complications. Therefore, newer P2Y12 blockers are recommended in first intention, 
over clopidogrel, in case of ACS [3,4,7]. They ensure an optimized protection regarding ischemic recurrence in comparison to clopidogrel. On the other arm, bleeding risk increases in line with DAPT duration regardless of the P2Y12 blocker chosen [8]. Even if 12 months remains the gold standard, a significant proportion of patients would benefit from DAPT duration adjustment and need to be identified.

\section{Minimal duration of DAPT after ACS: evidence supporting DAPT shorter than 12 months post ACS}

After PCI for an ACS the benefit related to DAPT is double. Firstly, DAPT is essential to reduce the risk of stent thrombosis and target lesion revascularization at the coronary site of PCI. And secondarily, patients having an ACS are at high risk of other location recurrent ischemic event, which can be prevented by DAPT [9].

Regarding the risk of stent thrombosis, the development of newer device allowed over time a reduction of DAPT duration [10]. While with first generation drug eluting stent 1 year DAPT has been recommended to prevent late ST, with last generation drug eluting stent (biodegradable polymer or polymer free) DAPT duration can be significantly reduced [11].

Studies randomly compared bare metal stent versus last generation drug eluting stent with a DAPT of 1 month in patients with high bleeding risk [12-14]. All led to the same conclusions that newer drug eluting stent are superior to bare metal stent in terms of ischemic recurrence despite one month DAPT. Sub analyses were performed to assess this superiority in ACS patients, with similar results [15]. Therefore, even if a relatively low number of patients has been assessed, it seems acceptable in cases of very high bleeding risk to reduce the DAPT duration to 1 month with the use of last generation drug eluting stent even after an ACS. However, this one month duration should be reserved to very selected (and infrequent) cases [7].

Data from meta-analysis and PRECISE DAPT (predicting bleeding complications in patients undergoing stent implantation and subsequent dual antiplatelet therapy) study support a reduction of DAPT duration to 3 to 6 months in cases of high bleeding risk ACS patients $[8,16,17]$. Those trials have been designed primarily based on the fact that major bleeding on DAPT has an impact on mortality after ACS that could be even greater than recurrent MI $[18,19]$. Short term DAPT has shown consistent non inferiority compared to 12 months DAPT [11]. Therefore, it seems that this duration could be an acceptable compromise between ischemic and bleeding protection in high bleeding risk patients after ACS.

A growing population represents patients with a very high bleeding risk and is defined by the need for triple therapy due to long term anticoagulation indication. In this cohort, it has been shown that the association of DAPT plus OAC increases significantly the risk of bleeding $[20,21]$. Therefore, this association should be as short as possible and the general consensus is to stop the DAPT at one month after an ACS to maintain a single antiplatelet agent in addition to oral anticoagulation [7,22]. However, in cases of very high bleeding risk, DAPT could be omitted and replaced by the association of OAC plus clopidogrel [7,22]. Regarding the anticoagulation agent, data are in favor of the use of non-vitamin $\mathrm{K}$ antagonist anticoagulant $[23,24]$. Clopidogrel is the only P2Y12 blocker recommended as part of the DAPT in those patients [7]. Once more, according to the ischemic bleeding risk evaluation the triple therapy period could be extended if well tolerated to 3 to 6 months.

\section{Evidence for longer DAPT duration after ACS: evidence supporting DAPT longer than 12 Mo post ACS}

There is clear evidence that some patients at high ischemic risk will benefit from prolonged treatment beyond 12 months after ACS. The data from the CHARISMA (Clopidogrel and Aspirin versus Aspirin Alone for the Prevention of Atherothrombotic Events), DAPT (Twelve or 30 Months of Dual Antiplatelet Therapy after Drug-Eluting Stents), PEGASUS (Long-Term Use of Ticagrelor in Patients with Prior Myocardial Infarction) and COMPASS (Rivaroxaban with or without Aspirin in Stable Cardiovascular Disease) studies show that in selected patients, opting for the prolongation and/or optimization of antithrombotic strategy over 1 year (prolonged platelet anti-aggregation dual therapy or aspirin-low dose and rivaroxaban combination) is associated with a significant reduction of recurrence of ischemic events and may be associated with mortality reduction in comparison with single antiplatelet agent [25-28].

The analysis of the pilot studies (CURE, PLATO, and TRITON TIMI) and data from registries showed that the risk of recurrence of cardiovascular events becomes lower after 12 months of DAPT but still persists and affect patient's prognostic $[1,5,6]$. Indeed, patients with ACS presentation are by definition at high ischemic risk after PCI. As early as 2007, an analysis of the CHARISMA trial showed, in patients with a history of myocardial infarction or stroke, a signal for prolongation of DAPT duration (aspirin clopidogrel) up to 30 months [25], with lower rates of primary endpoint despite an increase in moderate bleeding. As a result, the prolongation of DAPT beyond the pre-established 12-month period was tested in randomized clinical trials. The DAPT trial tested the prolongation of aspirin plus a thienopyridine at 12 months of ACS versus thienopyridine cessation [28]. This study showed contrasting results. Indeed, DAPT prolongation leads to a persistent reduction in the risk of recurrent cardiovascular events (confirming the existence of this risk after 12 months), but this is counterbalanced by an excess of bleeding and non-cardiovascular mortality. The PEGASUS-TIMI 54 study enrolled patients with a history of myocardial infarction for more than one year, who were randomized to receive, in addition to aspirin, ticagrelor or placebo [27]. At the end of the 33-month follow-up, it appears that patients on aspirin alone are exposed to a linear risk of recurrent cardiovascular event, comparable to the first or second year post-infarction. With ticagrelor, the risk of recurrent ischemic event is decreased with a persistent benefit at 3 years. The risk reduction affected all patients, including those who did not have coronary angioplasty for ACS. Compared with placebo, the risk of bleeding was increased with ticagrelor, but the risk of fatal hemorrhage was comparable and the overall benefit / risk ratio was in favor of ticagrelor.

As a result, the current challenge remains to target the subgroups of patients who will benefit from this DAPT duration adaptations. Indeed, DAPT prolongation is associated with reduction of ischemic recurrence counterbalanced by a sure risk of bleeding. Therefore, the ischemic bleeding evaluation is central and should be reassessed during follow up to guide DAPT duration.

\section{De-escalation strategies after ACS}

Increase of platelet reactivity during ACS is mainly observed in the early days/weeks after index event [29]; therefore deescalation strategies with early potent antiplatelet treatment in 
the acute phase followed by a less potent antiplatelet regimen has been recently investigated in clinical studies. This hypothesis is also partially supported by post hoc analysis from PLATO and TRITON-TIMI 38, showing greater ischemic benefit of more potent antiplatelet drugs in the early post ACS phase, while bleeding events occurred during the entire follow-up including the chronic phase $[30,31]$.

Results from Testing Responsiveness to Platelet Inhibition on Chronic Antiplatelet Treatment for Acute Coronary Syndromes (TROPICAL-ACS) study have been recently published [32]. 2619 patients with PCI for ACS were randomized to either standard treatment with prasugrel for 12 months (1306 patients, control group) or a stepdown regimen (1 week prasugrel followed by 1 week clopidogrel and platelet function-guided maintenance therapy with clopidogrel or prasugrel from day 14 after hospital discharge; 1304 patients, guided de-escalation group). In this deescalation group, patients with HTPR were switched back to prasugrel (39\%) and patient without HTPR were maintained on clopidogrel for 1 year. At 1 year, the combined primary endpoint (CV death, MI, stroke, bleeding BARC $\geq 2$ ) occurred in 95 patients (7\%) in the guided de-escalation group and in 118 patients (9\%) in the control group ( $\mathrm{p}$ non-inferiority $=0.0004$; HR $0.8195 \% \mathrm{CI} 0.62-$ 1.06 , p superiority $=0.12$ ). The ischemic components of the primary endpoint occurred in 32 patients $(3 \%)$ in the guided deescalation group and in 42 patients (3\%) in the control group (HR $0.7795 \%$ CI $0.48-1.21 ; p=0.25$ ), indicating that early de-escalation did not result in an increased risk of ischemic events ( $p$ noninferiority $=0.0115$ ). The incidence of the key secondary endpoint of BARC 2 or higher bleedings was $5 \%$ (64 events) in the guided de-escalation group versus $6 \%$ (79 events) in the control group (HR 0.82 95\%CI 0.59-1.13; $p=0.23$ ). The Timing Of Platelet Inhibition after acute Coronary syndrome (TOPIC) study is a monocentric trial comparing in patients one month after ACS continuation of DAPT with aspirin and newer P2Y12 blocker, or de-escalation to aspirin plus clopidogrel $[33,34]$. The main study results showed that the de-escalation strategy did reduce the incidence of bleeding BARC $\geq 2$ ( $4.0 \%$ vs. $14.9 \%$ HR $0.3095 \%$ CI $0.18-0.50, p<0.01)$ ) while the ischemic events (9.3\% vs. $11.5 \%$ HR $0.8095 \%$ CI $0.50-1.29, p=0.36)$ ) were not different between the two groups. Overall, TROPICAL ACS and TOPIC suggested that de-escalation from newer P2Y12 blocker to clopidogrel after an ACS may reduce the risk of bleeding complications without apparent increase risk of ischemic events, and could be guided by platelet function testing. Most recent guidelines suggest that an approach of DAPT de-escalation guided by platelet function testing may be considered in ACS patients as an alternative to 12 months potent platelet inhibition, especially for patients deemed unsuitable for maintained potent platelet inhibition (Class IIb Level B) [7,35]. The key remaining challenge will be the "patient selection" to define which patient is the good candidate for de-escalation integrating both ischemic and bleeding risks and which one deserve longer potent DAPT.

\section{Other antithrombotic strategies after ACS}

As discussed earlier, the risk of ischemic recurrences is not meaningless after the first 12 months following an ACS. We have seen that DAPT prolongation may be beneficial in this setting, despite non consistent findings. Therefore, other strategies have been developed and adding small dose of anticoagulant to antiplatelet agent has been tested in COMPASS study [26]. In a population of 27,395 patients with history of coronary artery disease or peripheral artery disease $>1$ year, the combination of aspirin $(<100 \mathrm{mg} /$ day $)$ and low dose rivaroxaban (2.5 twice daily) did reduce the primary endpoint of cardiovascular death, stroke and myocardial infarction in comparison to aspirin alone (HR $0.7695 \% \mathrm{CI}$ $0.66-0.86 p<0.001$ ) and rivaroxaban $5 \mathrm{mg}$ twice daily (HR0.90
95\%CI0.79 - $1.03 p=0.12$ ). Notably the association low dose anticoagulant plus aspirin did reduce the all-cause mortality versus aspirin alone. Major bleeding was increased in the combination group mostly led by non-fatal gastro intestinal bleeding. Therefore, a new strategy is now available for high risk patients 12 months after an ACS. DAPT cessation and introduction of low doses rivaroxaban may have a good efficacy safety profile for selected patients and its adoption in routine practice needs to be evaluated.

Another antithrombotic strategy consists in dropping aspirin shortly after the event to continue a single antiplatelet therapy with a P2Y12 blocker, and therefore reduce the risk of bleeding. It has been tested in the GLOBAL LEADERS trial comparing one month of aspirin plus ticagrelor followed by 23 months of ticagrelor only, versus aspirin plus ticagrelor for 12 months followed by aspirin only for the next 12 months [36]. At 2 years, ticagrelor in combination with aspirin for 1 month followed by ticagrelor alone for 23 months was not superior to 12 months of standard dual antiplatelet therapy followed by 12 months of aspirin alone in the prevention of all-cause mortality or new Q-wave myocardial infarction 2 years after percutaneous coronary intervention. Other ongoing studies are currently testing dropping aspirin and continuing P2Y12 inhibitor monotherapy and results will be available shortly $[37,38]$.

\section{Individualization of DAPT duration: scores and latest guidelines}

In the latest European guidelines, there is a room for DAPT duration adjustment after ACS [7]. The document allows a reduction of DAPT duration to 6 months in cases of high bleeding risk (level IIa B). On the other arm, this duration could be prolonged to 36 months in cases of high thrombotic risk if DAPT is well tolerated at 12 months (level IIb A). It has been repetitively showed that the bleeding risk associated with DAPT is increasing along with DAPT duration regardless of the type of P2Y12 blockers [39,40]. Therefore, to assess the bleeding risk of the patients Guidelines recommend to use validated scores. The PRECISE DAPT score has been designed to evaluate the risk of bleeding during the index hospitalisation for ACS [8]. It has been developed and validated retrospectively in large, randomized, patient cohorts comparing the duration of DAPT after ACS. The PRECISE DAPT score is a fiveitem risk score that identifies patients with a high bleeding risk after ACS, concluding that longer duration of DAPT significantly increases the bleeding risk in patients with a high PRECISE-DAPTscore. Conversely, shorter duration of DAPT in patients without a high bleeding risk increases ischaemic risk in patients with a low PRECISE DAPT-score. The defined cut off for PRECISE DAPT score is 25. In patients with a PRECISE DAPT higher than 25 the DAPT could be reduced after an ACS to 6 months instead of 12 month because the bleeding risk is continuing.

The DAPT score has been developed following the DAPT trial, to help clinicians decide whether DAPT with thienopyridine should be continued after 12 months [41]. This 9 items score could be used to predict the risk of ischemic and bleeding events from 12 months to 30 months after PCI and can be calculated online. Using this score, patients with a score $\geq 2$ are predicted to benefit from prolonged DAPT since the risk of an ischemic event may outweigh the bleeding risk. On the other hand, a patient with a score $<2$ is predicted to be harmed by extended duration DAPT since his bleeding risk may outweigh the risk of an ischemic event.

On top of those scores, which should be calculated for all ACS patients, clinical evaluation is essential. Patients (age, weight, previous ST or bleeding...) and procedural (length and number of stents, bifurcation, left main stenting) features need to be associated to the ischemic and bleeding risk balance evaluation and therefore DAPT duration decision [42] (Fig. 1). 

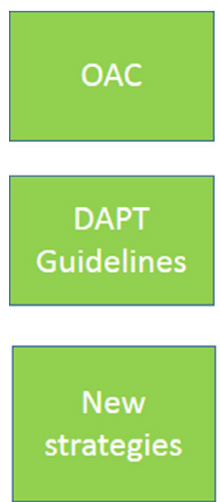
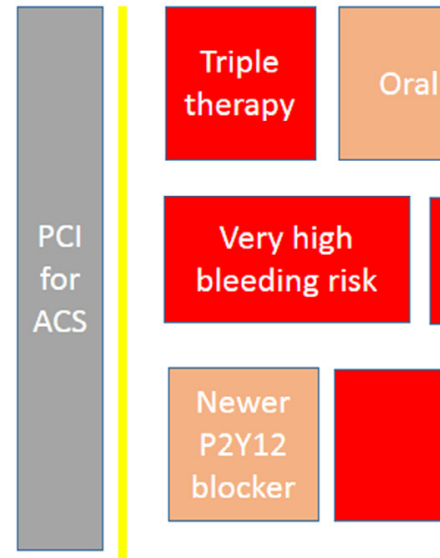

Oral anticoagulant + single antiplatelet

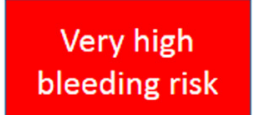

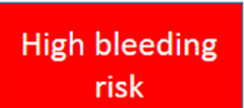

risk

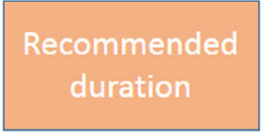

\section{PRECISE DAPT} score
De-escalation to clopidogrel
High ischemic risk
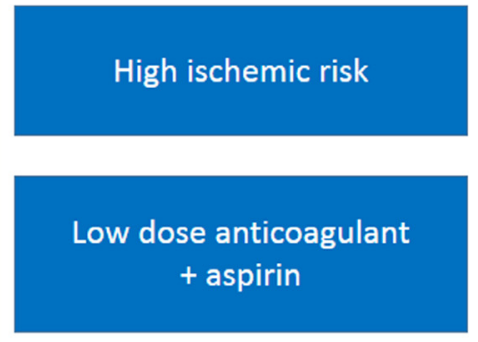

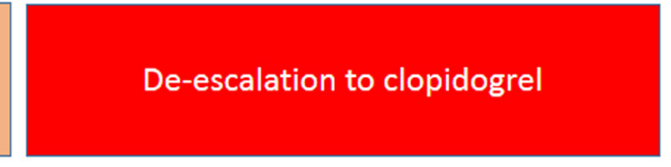

DAPT

score

\section{Bleeding risk $>$ ischemic risk Ischemic risk > bleeding risk Ischemic risk = bleeding risk}

Fig. 1. Dual antiplatelet strategies after acute coronary syndrome.

\section{Conclusion and practical algorithm}

In conclusion, all the strategies aiming to optimize the ischemic protection after an ACS are associated with an increase hazard of bleeding. Therefore, the selection of patients who will benefit for antithrombotic treatment optimization is essential. The ischemic and bleeding risk should be evaluated first during the index event, and then reassessed at 6 and 12 months for DAPT continuation. At 12 months in patients with high risk of ischemic recurrences and low bleeding risk the option could be to continue on DAPT, with possible de-escalation if not done before, or association of low dose rivaroxaban plus aspirin.

\section{References}

[1] Yusuf S, Zhao F, Mehta SR, Chrolavicius S, Tognoni G, Fox KK. Clopidogrel in unstable angina to prevent recurrent events trial investigators. Effects of clopidogrel in addition to aspirin in patients with acute coronary syndromes without ST-segment elevation. N Engl J Med 2001;345:494-502.

[2] Mehta SR, Yusuf S, Peters RJ, Bertrand ME, Lewis BS, Natarajan MK, et al. Clopidogrel in unstable angina to prevent recurrent events trial (CURE) investigators. Effects of pretreatment with clopidogrel and aspirin followed by long-term therapy in patients undergoing percutaneous coronary intervention: the PCI-CURE study. Lancet 2001;358:527-33.

[3] Levine GN, Bates ER, Bittl JA, Brindis RG, Fihn SD, Fleisher LA, et al. 2016 ACC/AHA guideline focused update on duration of dual antiplatelet therapy in patients with coronary artery disease: a report of the American College of Cardiology/American Heart Association Task Force on Clinical Practice Guidelines: an update of the 2011 ACCF/AHA/SCAI guideline for percutaneous coronary intervention, 2011 ACCF/AHA guideline for coronary artery bypass graft surgery, 2012 ACC/AHA/ACP/AATS/PCNA/SCAI/STS guideline for the diagnosis andmanagement of patients with stable ischemic heart disease, 2013 ACCF/AHA guideline for the management of ST-elevation myocardial infarction, 2014 ACC/AHA guideline for the management of patients with non-ST-elevation acute coronary syndromes, and 2014 ACC/AHA guideline on perioperative cardiovascular evaluation andmanagement of patients undergoing noncardiac surgery. J Am Coll Cardiol 2016;68(10):1082-115.

[4] Valgimigli M, Bueno H, Byrne RA, Collet JP, Costa F, Jeppsson A, et al. 2017 ESC focused update on dual antiplatelet therapy in coronary artery disease developed in collaboration with EACTS. The task force for dual antiplatelet therapy in coronary artery disease of the European Society of Cardiology (ESC) and of the European Association for Cardio-thoracic Surgery (EACTS). Eur Heart J 2017;39(3):213-60.
[5] Wiviott SD, Braunwald E, McCabe CH, Montalescot G, Ruzyllo W, Gottlieb S, et al. TRITON-TIMI 38 Investigators. Prasugrel versus clopidogrel in patients with acute coronary syndromes. N Engl J Med 2007;357:2001-15.

[6] Wallentin L, Becker RC, Budaj A, Cannon CP, Emanuelsson H, Held C, et al., PLATO Investigators, Freij A, Thorsén M. Ticagrelor versus clopidogrel in patients with acute coronary syndromes. N Engl J Med 2009;36:1045-57.

[7] Neumann FJ, Sousa-Uva M, Ahlsson A, Alfonso F, Banning AP, Benedetto UESC Scientific Document Group. 2018 ESC/EACTS guidelines on myocardial revascularization. Eur Heart J 2018;10:1093.

[8] Costa F, van Klaveren D, James S, Heg D, Räber L, Feres F. Derivation and validation of the predicting bleeding complications in patients undergoing stent implantation and subsequent dual antiplatelet therapy (PRECISE-DAPT) score: a pooled analysis of individual-patient datasets from clinical trials. Lancet 2017;389(10073):1025-34.

[9] Palmerini T, Benedetto U, Bacchi-Reggiani L, Della Riva D, Biondi-Zoccai G, Feres F, et al. Mortality in patients treated with extended duration dual antiplatelet therapy after drug eluting stent implantation: a pairwise and Bayesian network meta-analysis of randomised trials. Lancet 2015;385:2371-82.

[10] Palmerini T, Biondi-Zoccai G, Della Riva D, Mariani A, Sabaté M, Smits PC, et al. Clinical outcomes with bioabsorbable polymer- versus durable polymer-based drug-eluting and bare-metal stents: evidence from a comprehensive network meta-analysis. J Am Coll Cardiol 2014;63:299-307.

[11] Moon JY, Franchi F, Rollini F, Angiolillo DJ. Evolution of coronary stent technology and implications for duration of dual antiplatelet therapy. Prog Cardiovasc Dis 2018;60:478-90.

[12] Valgimigli M, Patialiakas A, Thury A, McFadden E, Colangelo S, Campo G, et al. Zotarolimus-eluting versus bare-metal stents in uncertain drug-eluting stent candidates. J Am Coll Cardiol 2015;65(8):805-15.

[13] Urban P, Meredith IT, Abizaid A, Pocock SJ, Carrié D, Naber C, et al. Polymer-free drug-coated coronary stents in patients at high bleeding risk. N Engl J Med 2015;373(21):2038-47.

[14] Varenne O, Cook S, Sideris G, Kedev S, Cuisset T, Carrié D, et al. Drug-eluting stents in elderly patients with coronary artery disease (SENIOR): a randomised single-blind trial. Lancet 2018;391(10115):41-50.

[15] Naber CK, Urban P, Ong PJ, Valdes-Chavarri M, Abizaid AA, Pocock SJLEADERS FREE Investigators. Biolimus-A9 polymer-free coated stent in high bleeding risk patients with acute coronary syndrome: a leaders free ACS sub-study. Eur Heart J 2017;38(April (13)):961-9.

[16] Gwon HC, Hahn JY, Park KW, Song YB, Chae IH, Lim DS, et al. Six-month versus 12-month dual antiplatelet therapy after implantation of drug-eluting stents: the efficacy of xience/promus versus cypher to reduce late loss after stenting (EXCELLENT) randomized, multicenter study. Circulation 2012;125:505-13.

[17] Schulz-Schupke S, Byrne RA, Ten Berg JM, Neumann FJ, Han Y, Adriaenssens T, et al. ISAR-SAFE: a randomized, double-blind, placebo-controlled trial of 6 vs. 12 months of clopidogrel therapy after drug-eluting stenting. Eur Heart J 2015;36:1252-63. 
[18] Pocock SJ, Mehran R, Clayton TC, Nikolsky E, Parise H, Fahy M, et al. Prognostic modeling of individual patient risk and mortality impact of ischemic and hemorrhagic complications: assessment from the acute catheterization and urgent intervention triage strategy trial. Circulation 2010;121:43-51.

[19] Mehran R, Pocock S, Nikolsky E, Dangas GD, Clayton T, Claessen BE, et al. Impact of bleeding onmortality after percutaneous coronary intervention results from a patient-level pooled analysis of the REPLACE-2 (randomized evaluation of PCI linking angiomax to reduced clinical events), ACUITY (acute catheterization and urgent intervention triage strategy), and HORIZONS-AMI (harmonizing outcomes with revascularization and stents in acute myocardial infarction) trials. JACC Cardiovasc Interv 2011;4:654-64.

[20] Dewilde WJ, Oirbans T, Verheugt FW, Kelder JC, De Smet BJ, Herrman JP, et al. Use of clopidogrel with or without aspirin in patients taking oral anticoagulant therapy and undergoing percutaneous coronary intervention: an open-label, randomised, controlled trial. Lancet 2013;381(9872):1107-15.

[21] Fiedler KA, Maeng M, Mehilli J, Schulz-Schüpke S, Byrne RA, Sibbing D, et al. Duration of triple therapy in patients requiring oral anticoagulation after drug-eluting stent implantation: the ISAR-TRIPLE trial. J Am Coll Cardiol 2015;65(16):1619-29.

[22] Angiolillo DJ, Goodman SG, Bhatt DL, Eikelboom JW, Price MJ, Moliterno DJ, Cannon CP, Tanguay JF, Granger CB, Mauri L, Holmes DR, Gibson CM, Faxon DP. Antithrombotic therapy in patients with atrial fibrillation treated with oral anticoagulation undergoing percutaneous coronary intervention. Circulation 2018;138:527-36

[23] Gibson CM, Mehran R, Bode C, Halperin J, Verheugt FW, Wildgoose P, et al. Prevention of bleeding in patients with atrial fibrillation undergoing PCI. N Engl J Med 2016;375(25):2423-34.

[24] Cannon CP, Bhatt DL, Oldgren J, Lip GYH, Ellis SG, Kimura T, et al. Dual antithrombotic therapy with dabigatran after PCI in atrial fibrillation. N Engl JMed 2017;377(16):1513-24.

[25] Bhatt DL, Flather MD, Hacke W, Berger PB, Black HR, Boden WE, et al. Patients with prior myocardial infarction, stroke, or symptomatic peripheral arterial disease in the CHARISMA trial. J Am Coll Cardiol 2007;49(19):1982-8.

[26] Eikelboom JW, Connolly SJ, Bosch J, Dagenais G, Dyal L, Lanas F, et al. Rivaroxaban with or without aspirin in stable cardiovascular disease. N Engl J Med 2017;377(14):1319-30.

[27] Bonaca MP, Bhatt DL, Cohen M, Steg PG, Storey RF, Jensen EC, et al. Long-term use of ticagrelor in patients with prior myocardial infarction. N Engl J Med 2015;372(19):1791-800.

[28] Mauri L, Kereiakes DJ, Yeh RW, Driscoll-Shempp P, Cutlip DE, Steg PG, et al. Twelve or 30 months of dual antiplatelet therapy after drug-eluting stents. N Engl J Med 2014;371(23):2155-66.

[29] Price MJ, Berger PB, Teirstein PS, Tanguay J-F, Angiolillo DJ, Spriggs DGRAVITAS Investigators. Standard- vs high-dose clopidogrel based on platelet function testing after percutaneous coronary intervention: the GRAVITAS randomized trial. JAMA 2011;305:1097-105.

[30] Antman EM, Wiviott SD, Murphy SA, Voitk J, Hasin Y, Widimsky P, et al. Early and late benefits of prasugrel in patients with acute coronary syndromes undergoing percutaneous coronary intervention: a TRITON-TIMI 38 (TRial to Assess Improvement in Therapeutic Outcomes by Optimizing Platelet InhibitioN with Prasugrel-Thrombolysis In Myocardial Infarction) analysis. J Am Coll Cardiol 2008;51:2028-33.

[31] Becker RC, Bassand JP, Budaj A, Wojdyla DM, James SK, Cornel JH, et al. Bleeding complications with the P2Y12 receptor antagonists clopidogrel and ticagrelor in the PLATelet inhibition and patient Outcomes (PLATO) trial. Eur Heart J 2011;32:2933-44.
[32] Sibbing D, Aradi D, Jacobshagen C, Gross L, Trenk D, Geisler TTROPICAL-ACS Investigators. Guided de-escalation of antiplatelet treatment in patients with acute coronary syndrome undergoing percutaneous coronary intervention (TROPICAL-ACS): a randomised, open-label, multicentre trial. Lancet 2017;390:1747-57.

[33] Cuisset T, Deharo P, Quilici J, Johnson TW, Deffarges S, Bassez C, et al. Benefit of switching dual antiplatelet therapy after acute coronary syndrome: the TOPIC (timing of platelet inhibition after acute coronary syndrome) randomized study. Eur Heart J 2017;38:3070-8.

[34] Deharo P, Quilici J, Camoin-Jau L, Johnson TW, Bassez C, Bonnet G, et al. Benefit of switching dual antiplatelet therapy after acute coronary syndrome according to on-treatment platelet reactivity: the TOPIC-VASP pre-specified analysis of the TOPIC randomized study. JACC Cardiovasc Interv 2017;10:2560-70.

[35] Angiolillo DJ, Rollini F, Storey RF, Bhatt DL, James S, Schneider DJ, Sibbing D, So DYF, Trenk D, Alexopoulos D, Gurbel PA, Hochholzer W, De Luca L, Bonello L, Aradi D, Cuisset T, Tantry US, Wang TY, Valgimigli M, Waksman R, Mehran R, Montalescot G, Franchi F, Price MJ. International expert consensus on switching platelet P2Y12 receptor-inhibiting therapies. Circulation 2017;136:1955-75

[36] Vranckx P, Valgimigli M, Jüni P, Hamm C, Steg PG, Heg D, van Es GA, McFadden EP, Onuma Y, van Meijeren C, Chichareon P, Benit E, Möllmann $H$, Janssens L, Ferrario M, Moschovitis A, Zurakowski A, Dominici M, Van Geuns RJ, Huber K, Slagboom T, Serruys PW, Windecker SGLOBAL LEADERS investigators. Ticagrelor plus aspirin for 1 month, followed by ticagrelor monotherapy for 23 months vs aspirin plus clopidogrel or ticagrelor for 12 months, followed by aspirin monotherapy for 12 months after implantation of a drug-eluting stent: a multicentre, open-label, randomised superiority trial. Lancet 2018;392:940-9.

[37] Baber U, Dangas G, Cohen DJ, Gibson CM, Mehta SR, Angiolillo DJ, Pocock SJ, Krucoff MW, Kastrati A, Ohman EM, Steg PG, Badimon J, Zafar MU, Chandrasekhar J, Sartori S, Aquino M, Mehran R. Ticagrelor with aspirin or alone in high-risk patients after coronary intervention: rationale and design of the TWILIGHT study. Am Heart J 2016;182:125-34.

[38] Capodanno D, Mehran R, Valgimigli M, Baber U, Windecker S, Vranckx P, Dangas G, Rollini F, Kimura T, Collet JP, Gibson CM, Steg PG, Lopes RD, Gwon HC, Storey RF, Franchi F, Bhatt DL, Serruys PW, Angiolillo DJ. Aspirin-free strategies in cardiovascular disease and cardioembolic stroke prevention. Nat Rev Cardiol 2018:15:480-96.

[39] Valgimigli M, Campo G, Monti M, Vranckx P, Percoco G, Tumscitz C, et al. Short- versus long-term duration of dual-antiplatelet therapy after coronary stenting: a randomized multicenter trial. Circulation 2012;125(16):2015-26.

[40] Palmerini T, Sangiorgi D, Valgimigli M, Biondi-Zoccai G, Feres F, Abizaid A, et al. Short- versus long-termdual antiplatelet therapy after drug-eluting stent implantation: an individual patient data pairwise and network meta-analysis. J Am Coll Cardiol 2015;65(11):1092-102.

[41] Yeh RW, Secemsky E, Kereiakes DJ, Normand SL, Gershlick AH, Cohen DJ, et al. Development and validation of a prediction rule for benefit and harm of dual antiplatelet therapy beyond one year after percutaneous coronary intervention: an analysis fromthe randomized dual antiplatelet therapy study. JAMA 2016;315(16):1735-49.

[42] Cuisset T, Verheugt FWA, Mauri L. Update on antithrombotic therapy after percutaneous coronary revascularisation. Lancet 2017;390(10096):810-20. 